\title{
"Unmotivated Bias" and Partisan Hostility: Empirical Evidence
}

\author{
Daniel F. Stone \\ Bowdoin College
}

August 2018*

\begin{abstract}
Extreme partisan animosity has been on the rise in the US and is prevalent around the world. This hostility is typically attributed to social group identity, motivated reasoning, or a combination thereof. In this paper, I empirically examine a novel explanation: the "unmotivated" cognitive bias of overprecision (overconfidence in precision of beliefs). Overprecision could cause partisan hostility indirectly via inflated confidence in one's own ideology, partisan identity, or perceptions of social distance between the parties. Overprecision could also cause this hostility directly by causing excessively strong inferences from observed information that is either skewed against the out-party or simply misunderstood. Using a nationally representative sample, I find consistent support for direct effects of overprecision and mixed support for indirect effects. The point estimates imply a one standard deviation increase in a respondent's overprecision predicts as much as a 0.71 standard deviation decline in relative out-party favorability.
\end{abstract}

Keywords: affective polarization, partyism, overprecision, motivated reasoning, media bias

*Department of Economics, Bowdoin College, dstone@bowdoin.edu. I thank Erik Snowberg and Pietro Ortoleva for very helpful comments in the early stages of this project and for providing the 2010 and 2011 CCES data, and thank Snowberg, Dan Kahan, Don Moore, John Barry Ryan, Gaurav Sood, and Steven W. Webster for especially detailed comments and discussion. I also thank Chris Tausanovitch and Christopher Warshaw for providing the issue-preference ideology estimates for the 2011 CCES, and Dan Wood, Steven Sloman, William Minozzi, Yanna Krupnikov, Gabor Simonovits, Stephen Ansolabehere, Jesse Shapiro, Kevin Thom, Tim Wilson and participants at the Behavioral Models of Politics conference (Pittsburgh) for also providing helpful comments. 
"There's no sense in being precise when you don't even know what you're talking about." -John von Neumann

\section{Introduction}

Recent political polarization in the US has attracted much attention from scholars across the social sciences, with good reason. It is clear now that the actions and rhetoric of politicians of the two major parties have diverged sharply over the last half-century (Barber and McCarty, 2015; Andris et al., 2015; Gentzkow et al., 2015). It is more ambiguous to what extent, if any, voter ideologies have also become polarized (Hill and Tausanovitch, 2015; Lelkes, 2016). In just the last several years, however, more clear evidence has emerged regarding another type of voter polarization - affective polarization - that voters' feelings about the parties have polarized over time (Iyengar et al., 2012; Lelkes, 2016). In particular, hostility toward the "out-party," sometimes called partyism for short (Sunstein, 2015), has grown sharply, even controlling for partisan sorting, as shown in Figure 1. Partyism contributes to partisan conflict and gridlock, and has other significant political and social implications (Hetherington and Rudolph, 2015; Huber and Malhotra, 2017). ${ }^{1}$

What causes partyism, and changes in partyism? Much of the literature in this area focuses on growth in "social distance" between the parties (see, e.g., Iyengar and Westwood, 2015) and strengthened partisan identity and "tribalistic" thinking (Greene, 2014; Mason, 2018). In many papers it is taken as given that people automatically dislike those in different social groups, more so as we identify more strongly with the in-group and/or perceive larger differences from the out-group. Papers that discuss or analyze the cognitive basis for such dislike focus on social group-based motivated beliefs - that partisans prefer (consciously or otherwise) to believe in their own group's strengths, and the out-group's weaknesses in various dimensions. ${ }^{2}$

${ }^{1}$ While very recent partyism in the US is the focus of this paper, partyism is certainly not unique to this environment. Westwood et al. (2015) show that partyism is prevalent around the world and see, for example, Selinger (2016) for discussion of historical partisan hostility.

${ }^{2}$ See Haidt (2012) and Greene (2014) for books summarizing related psychology and neuroscience research. See also, e.g., Lelkes et al. (2015) and Rogowski and Sutherland (2015) 


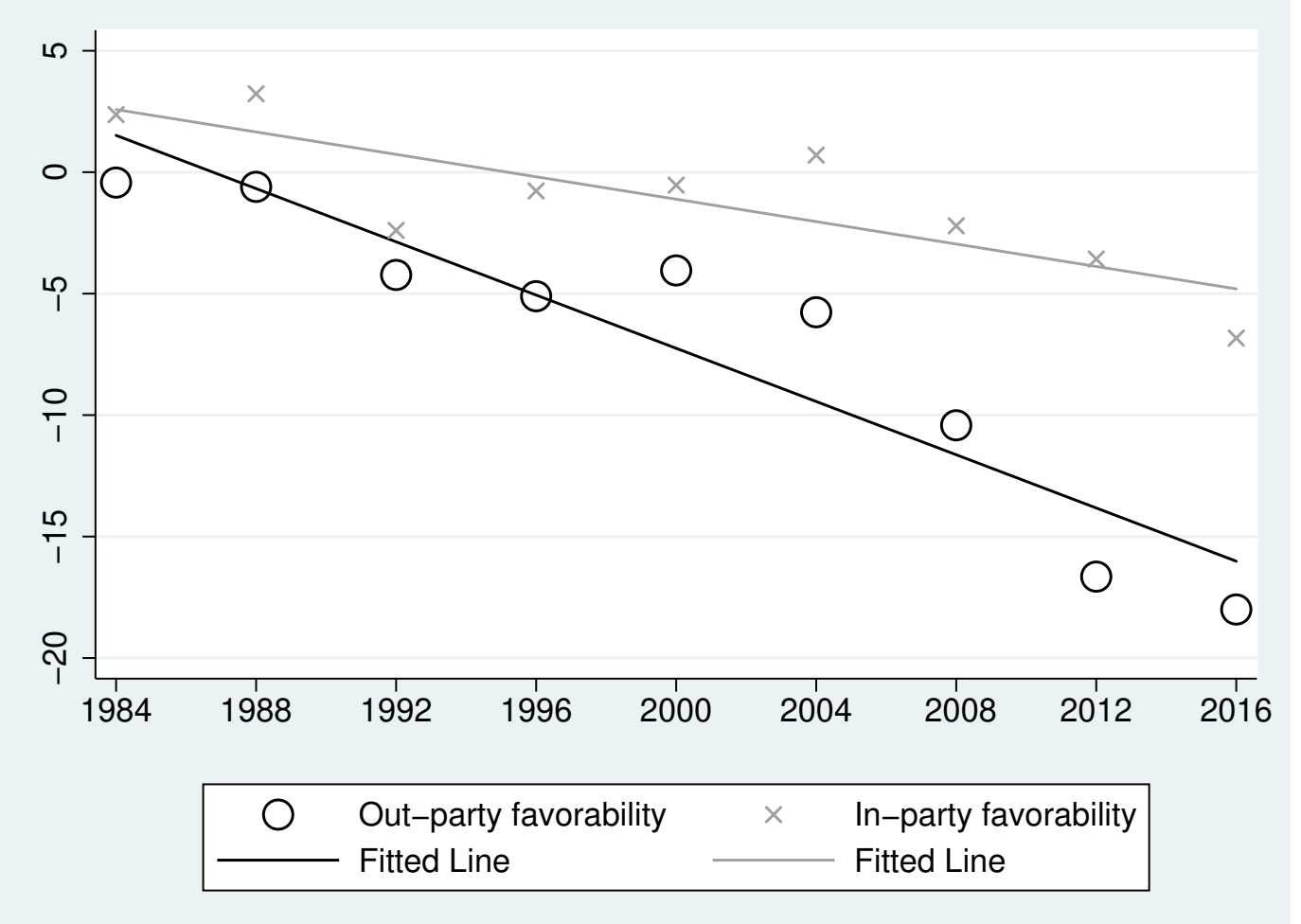

Figure 1: Ideology, demographic, and partisanship-adjusted changes in out- and in-party favorability ratings versus 1980, with linear trends. Each data point is an estimated year fixed effect (with omitted year 1980) from regression of dependent variable of in- or outparty thermometer ratings $(0-100 ; 0=$ "coldest" and $100=$ "warmest"; the standard measure of feelings about the parties used in this literature) with fixed effect controls for 7-point party identity and 7-point ideology (to control for party sorting), age, education, income, race, gender, and region, for American National Election Studies cumulative file data from presidential election years from 1980-2016. 
In this paper, I empirically study another possible cause of partisan hostility: "unmotivated" cognitive bias. The distinction from motivated bias is significant, as misperceptions held due to unmotivated bias may be more likely to be mitigated by exposure to information contradicting one's beliefs. That is to say, I study whether partisan conflict is due partly to relatively unintentional, and thus perhaps relatively correctible, misunderstanding.

It might seem intuitive that partyism is due to cognitive biases beyond social identitydriven motivated reasoning. We all know from experience that when people disagree, this tends to make them unfairly judge and dislike one another, whether they come from different social groups or not. The 2016 US presidential campaign was characterized by much conflict and hostility within both parties (Sanders versus Clinton for the Democrats, and Trump versus the field for Republicans). Thus, group identity theory does not seem to offer the complete explanation for partisan animosity.

However, to the best of my knowledge, there is no existing work (in economics or beyond) that directly empirically studies the relationship between partisan hostility and unmotivated cognitive bias of any type. The broader literatures on hostility between social groups, and on interpersonal animosity more generally, also largely neglect such cognitive bias. ${ }^{3}$ The lack of research on the relationship between bias and affective outcomes may be due to the historical distinction drawn between cognitive (thinking) and affective (feeling) psychological processes, a distinction that has more recently been called into question. ${ }^{4}$

The specific bias that I study is overconfidence in precision of beliefs, a.k.a., overprecision. for examples of political science papers that discuss the relevance of motivated reasoning to partisan hostility. Motivated beliefs and reasoning have recently begun to attract more attention in economics and were the subject of a symposium in a recent issue of the Journal of Economic Perspectives (see, e.g., Bénabou and Tirole (2016)).

${ }^{3}$ See, e.g., Tajfel (1978) and Rempel and Sutherland (2016) for work on social groups and on animosity more generally.

${ }^{4}$ For an example of the historical divide in psychology between cognition and affect, see Neisser (1971), and for an example of recent work critical of this divide, Pessoa (2008)). Bénabou and Tirole (2016) refer to work "on the interplay of emotions and informationprocessing ... [as] sometimes referred to as the 'affective revolution' or 'second cognitive revolution." 'Another reason for the lack of literature on bias and out-group dislike may be lack of clarity regarding the distinction between motivated and unmotivated bias. I discuss this issue further in the next section, and attempt to provide clarification. 
As I argue in more detail in Section 2, overprecision is an important over-arching bias that may affect partisan feelings for several reasons, both indirect and direct. Overprecision could lead to greater hostility indirectly by enhancing one's own political extremism and/or perceived social distance between the parties, in turn directly causing greater partyism for other reasons, such as motivated reasoning. Overprecision could also lead to greater out-party hostility directly by increasing confidence in observed information that superficially reflects negatively on the out-party, namely, extreme political actions by the out-party, as shown theoretically by Stone (2016), and or media content slanted against the out-party. Since these mechanisms (extremism of political actions and slanted media) have become more prevalent over time, they are also potentially relevant to the observed growth over time in partyism. (The empirical analysis is cross-sectional due to the nature of the data, as I discuss just below; I discuss the relationship between this analysis and the growth in partyism further at the end of Section 2.)

In Section 3, I describe the data, a 2011 module of the Cooperative Congressional Election Study (CCES), a representative sample with 1,000 respondents. This data set was developed and first used by Ortoleva and Snowberg (2015b), henceforth referred to as OS. ${ }^{5}$ In Section 3, I also discuss the method developed to calculate individual-level overprecision, and validation of this method. I describe the methods used for the empirical analysis in Section 4. Since motivated reasoning is the key alternative explanation for the outcome of partyism, I take extra steps to account for this confounding factor, including use of a control variable constructed to capture individual-level strength of motivated reasoning, and analysis of comparative statics that differ for motivated reasoning and overprecision. I also use pure confidence (in the accuracy of one's beliefs) as both a control variable and a placebo independent variable.

I present results in Section 5. I find mixed evidence regarding the indirect effects of bias on partyism, and consistent support for direct effects. Overall, the results suggest that overprecision plays a substantial role in driving partyism: the point estimates imply a one standard increase deviation in a respondent's overprecision predicts as much as a 0.71 standard

\footnotetext{
${ }^{5}$ The data set is now publicly available on the American Economic Review website.
} 
deviation decline in relative out-party favorability. The direct effect results are robust to inclusion of detailed controls for ideology, partisanship, perceived social distance between the parties, motivated reasoning, and pure confidence. I also show that overprecision effects do not increase with education (which they would likely do if they were merely proxying motivated reasoning effects Kahan, 2016), and present evidence of a specific cognitive channel, belief in the Obama "birther" theory (the theory that he was not born in the US), by which overprecision increases dislike (indicating that overprecision is not just a proxy for "mindless" emotional effects). Both results, and an additional placebo analysis, support the interpretation of the main direct effect results representing causal effects. However, I acknowledge that the establishment of causality is not completely clear, and should be studied further in future work. In the final section of the paper, I provide brief concluding remarks, including discussion of potential related future work.

\section{Related literature and hypotheses}

\subsection{Related political economics literature}

Before proceeding to discussion of related work on overprecision, I briefly discuss two related literatures from the broader fields of public choice and political economy. One is the literature on biases in voter beliefs. See Caplan (2002) for documentation of such biases on policy issues, and Caplan (2001) for a defense of the individual rationality of biased beliefs due to low private costs and potentially substantial private benefits, and Levy (2014) for more recent related work. See, e.g. Congleton (2001), for related work on rational ignorance. The present paper is similar in that I also study biases in political beliefs - about the Birther issue in particular, and implicitly about character traits and actions more broadly that might drive favorability ratings (Stone, 2016). Just as voters may face low private costs of holding biased beliefs on issues such as the benefits of free trade, the private costs of holding biased beliefs underlying favorability ratings of the parties are likely also low. My paper differs from this literature in that I do not focus on private benefits as the source of the biased beliefs, often (implicitly) assumed to be driven by motivated reasoning, but instead, study more incidental, 
unmotivated cognitive bias as the cause. ${ }^{6}$

Another broadly related economics literature is that on political polarization. There are numerous strands of this literature. For example, there is a body of theory and empirical work on rational divergence of opinions (e.g., Andreoni and Mylovanov, 2012; Cheng and Hsiaw, 2017), and there are a number of empirical papers on polarization of politicians and/or voters on other cognitive mechanisms (e.g., de Leon and Rizzi, 2016; DeVault, 2013; Jha et al., 2018). Some papers study the relationship between non-standard information processing and polarization in various ways; for example, Esponda and Pouzo (2016) show that politicians may rationally polarize in response to behavioral voters, and Fryer Jr et al. (2013) show that polarization can occur when individuals are Bayesian but process ambiguous signals in a simplified way. However, besides Ortoleva and Snowberg's work, there is perhaps surprisingly little empirical work linking cognitive bias to political polarization, and again no work, to my knowledge, on cognitive bias and affective polarization except Stone (2016).

\subsection{Background on overprecision}

Overconfidence is an especially ubiquitous and well-studied cognitive bias. It is now widely recognized in the behavioral economics literature that there are two major types of overconfidence: overprecision (over-estimation of the probability of holding correct beliefs or the precision of one's distribution of beliefs) and overoptimism (over-estimation of the probability of something one wishes to be true) (see, e.g., Grubb, 2015). Overprecision shrinks the variance of beliefs, while overoptimism shifts the mean. ${ }^{7}$

Overoptimism is more directly related to motivated reasoning, while overprecision is the most robust and widely observed type of overconfidence (Moore et al., 2015). Moreover, as mentioned in Section 1, overprecision is arguably an over-arching bias, i.e., a root cause of other more narrow biases. ${ }^{8}$ Empirically, overprecision indeed predicts other unmotivated biases

${ }^{6}$ See Schnellenbach and Schubert (2015) for a useful survey of the broader behavioral political economy literature with an emphasis on the Virginia School of public choice in particular.

${ }^{7}$ Moore and Healy (2008) discuss three types of overconfidence: overprecision, overplacement, and overestimation. Numerous later papers follow this taxonomy. In Grubb's taxonomy, which I follow because it is simpler, the latter two types are subsumed by over-optimism.

${ }^{8}$ Informally, the general importance of overprecision is reflected in several famous, perhaps 
(Hoppe and Kusterer, 2011; Noori, 2016).

\subsection{Unmotivated versus motivated bias}

The difference between overprecision and overoptimism reflects the general difference between unmotivated and motivated bias: the latter is due to believing what one wishes to be true, the former is due to cognitive heuristics and other quirks. While overprecision can appear to reflect motivational forces, it does not have to, as we may hold overly-precise beliefs about a negative outcome. For example, overprecision can cause a student who lacks confidence in his ability to be excessively certain in his pessimism and unwilling to exert effort to learn his true potential. In general, while unmotivated and motivated bias may be empirically correlated, they are certainly not collinear, and they are conceptually quite distinct. See Moore et al. (2015) for further discussion and evidence of overprecision not being driven by motivational effects. Moore et al. (2016) do note a "conspicuous" lack of literature directly addressing the relationship between motivation and overprecision, so this issue is still unresolved.

It should also be noted that the term unmotivated bias is not original to this paper, but is not used often in prior literature. ${ }^{9}$ But the term conveys a key distinction. An important comparative static that varies for the two types of bias is that overall cognitive ability and education should enhance the effects of motivated bias, as this ability makes us more likely to obtain cognitive motivational goals (see, e.g., Kahan (2016)), while we would not expect even clichéd, quotes: "The more you know, the more you don't know," (Aristotle); "Not to be absolutely certain is, I think, one of the essential things in rationality," (Bertrand Russell); "It ain't what you don't know that gets you into trouble. It's what you know for sure that just ain't so," (Mark Twain). Tetlock and Gardner (2015) write that WYSIATI ("what you see is all there is"), which is conceptually similar to overprecision (both imply overconfidence in one's knowledge), is "the mother of all cognitive illusions." The intuition for this idea, and related ideas reflected in the other quotes, is that in order to hold a biased belief, one must be unaware of the full extent of the bias (otherwise one would account for the bias). And this unawareness of bias is essentially equivalent to over-estimation of the accuracy of one's beliefs.

${ }^{9}$ Laibson and Zeckhauser (1998) may have been the first paper in economics to use this term. Since then, there have been very few others in economics to use it; it is used more often, though still sporadically, in other fields. The terms hot and cold cognition are used somewhat more often, but are not equivalent to motivated and unmotivated; motivated reasoning does not require a "hot" or aroused mental state to occur. Bénabou and Tirole (2016) refer to the class of "unmotivated" biases as: "mechanical failures' of inference due to bounded rationality or limited attention". 
overprecision effects to be enhanced this way.

\subsection{Partyism hypotheses: Indirect effects}

I first discuss hypotheses of indirect effects of overprecision on partyism, then discuss direct effects. While I argue that unmotivated bias as a cause of partisan hostility has been relatively under-studied, it has not been completely neglected. There is a strand of the very recent political science literature on affective polarization that studies this topic implicitly, focusing on biased perceptions of the out-party. In particular, several papers have shown that perceptions of differences between the parties are biased upward (Ahler, 2014; Rogowski and Sutherland, 2015; Levendusky and Malhotra, 2015), leading to greater social distance and thus, plausibly, greater out-party dislike. Similar literature from psychology includes Chambers and Melnyk (2006) and Westfall et al. (2015). Overprecision is plausibly closely related to the biases and ideas studied in these papers (though they tend not to study any particular biases explicitly, including overprecision). This literature thus motivates the first hypothesis that I examine for an indirect effect of overprecision on out-party dislike:

Hypothesis 1.A (H1.A): Partisans who are more overconfident in the precision of their beliefs perceive greater social distance from the out-party versus that of the in-party, ceteris paribus, which in turn increases relative dislike of the out-party, ceteris paribus.

H1.A conditions on holding an individual's own politics fixed. But it is also possible that bias drives dislike indirectly by playing a role in determining one's politics. This issue is the focus of OS's work: they study a formal model implying that overconfidence increases ideo-

logical extremism and strength of partisan identity, and present empirical results consistent with this prediction. From psychology, Fernbach et al. (2013) provide similar experimental evidence, showing that individuals who hold extreme issue positions are subject to the "illusion of understanding." Enhanced extremism and strength of partisan identity increase social distance and out-party dislike (Mason, 2015; Abramowitz and Webster, 2015). Thus the second and third indirect effects that I hypothesize are:

Hypothesis 1.B (H1.B): Partisans who are more overconfident in the precision of their beliefs are more politically extreme, ceteris paribus, which in turn increases relative out-party 
dislike, ceteris paribus.

Hypothesis 1.C (H1.C): Partisans who are more overconfident in the precision of their beliefs have stronger partisan identities, ceteris paribus, which in turn increases relative outparty dislike, ceteris paribus.

\subsection{Partyism hypotheses: Direct effects}

The primary focus of this paper is direct effects of overprecision on partyism (effects holding fixed social distance and group identity, i.e., holding fixed one's own ideology, partisanship, and/or perception of the out-party's ideology). This focus is motivated partly by a companion paper, Stone (2016). In that paper, a model is presented showing how two (unmotivated) cognitive biases can cause misinterpretation of political actions leading to increased dislike of the out-party, more so as the actions grow more extreme. I present a simplified version of this model in Appendix A.1 and show how these effects are exacerbated by overprecision. The basic intuition is that political actions reflect one's willingness to trade off private for social gains. More extreme actions reflect a stronger preference for private gains, i.e., being more selfserving, and less socially-minded. But the reasons for these extreme actions are more complex than observers realize. ${ }^{10}$ Consequently, observers who tend to, in general, over-estimate their knowledge and understanding, tend to draw excessively negative character inferences from observed political actions.

In the companion paper, I discuss how the model applies to other bilateral relationships outside of politics, such as spouses, in which motivational and group identity factors should be much less relevant. The fact that unjustified dislike - dislike based on misguided beliefs — does seem to occur regularly in such contexts (this is the source of plot tension in many fictional works, and why there is a market for marriage counselors) implies that motivated reasoning and tribalistic thinking are not the only elements underlying this phenomenon. It is very plausible that unmotivated biases contribute to discord in relationships more generally, and that overprecision would exacerbate these effects.

\footnotetext{
${ }^{10}$ Haidt (2012)'s work on unintentional under-estimation of differences in moral "tastes" across parties reflects related ideas.
} 
Another way that overprecision could cause out-party dislike directly is via judgments based on information obtained from the media. It is well known that people tend to prefer and be more likely to be exposed to politically congenial information via mass media, and to avoid uncongenial information; see, e.g., Martin and Yurukoglu (2017) for recent evidence. While motivational forces could cause one to be insufficiently skeptical of biased information from such sources, overprecision would very plausibly have the same effect. Indeed, the paper that coined the term "affective polarization," Iyengar et al. (2012), speculated that the increase in negative campaign advertising was a key cause of the phenomenon. That paper did not discuss the cognitive mechanisms underlying this effect but implied that media consumers would likely be naïve in interpreting this information.

It is also worth noting the substantial literature in psychology (Robinson et al., 1995; Graham et al., 2009; Chambers et al., 2013) showing that members of different parties think about moral values differently and misunderstand the moral thinking of out-party members, which could lead to too pessimistic a view of their morality and increased hostility between the parties. While I am not aware of any papers that directly discuss how unmotivated bias could play a role in forming these judgments, it seems plausible. Thus, there are several ways in which overprecision could directly increase partyism holding fixed other relevant factors such as ideological extremism. This hypothesis is stated formally as follows.

Hypothesis 2.A (H2.A): Partisans who are more overconfident in the precision of their beliefs feel more relative out-party dislike, ceteris paribus.

Several important and testable auxiliary hypotheses follow from the above discussion. First, the discussion in Section 2.2 implied that motivated reasoning effects would increase with cognitive ability, while this would not be true for overprecision (direct) effects. Thus, testing the next hypothesis would shed light on whether observed overprecision effects might be driven by motivated reasoning forces. ${ }^{11}$

Hypothesis 2.B (H2.B): The direct effects of overprecision on relative out-party dislike do

\footnotetext{
${ }^{11}$ This issue is much less relevant to indirect overprecision effects since we would not expect motivated reasoning to lead to evidence consistent with H1.B or H1.C. The threat is more plausible for H1.A, but it turns out that this hypothesis is not supported so we do not need to be concerned about alternative explanations for results supporting the hypothesis.
} 
not increase as cognitive ability increases, ceteris paribus.

Next, the discussion earlier in this subsection suggests that if overprecision direct effects are due to media exposure, then the overprecision effect should increase in the level of media exposure.

Hypothesis 2.C (H2.C): The direct effects of overprecision on relative out-party dislike increase as media exposure increases, ceteris paribus.

Finally, one may be concerned that observed overprecision effects could reflect other unobserved psychological factors. For example, partisans who have higher levels of overprecision may be more likely to be emotional and simply have stronger feelings about out-groups, even though those feelings are not based on false beliefs influenced by overprecision per sé. On the other hand, if overprecision does affect partyism for the reasons discussed above, then overprecision should increase confidence in false beliefs that reflect negatively on the out-party. I state this final hypothesis as follows.

Hypothesis 2.D (H2.D): Partisans who are more prone to overprecision are more likely to hold false beliefs that lead to greater relative out-party dislike, ceteris paribus.

Two additional remarks are in order before proceeding. First, as noted in Section 1, the hypotheses all refer to the cross-sectional relationship between overprecision and dislike, as the data set is cross-sectional, and an important question at hand is why is partyism so severe today. However, these hypotheses also relate to growth in dislike (affective polarization), as the mechanisms underlying the hypotheses (extremism in politician behavior, availability of anti-out-party information, and party sorting) have been exacerbated over time. ${ }^{12}$ Second, to be clear, I am not assuming that out-party dislike is due to bias; the dislike may be justified, at least for one party, and the empirical analysis allows for this (since the analysis focuses on relative dislike - disliking the other party more than one's own - it cannot be objectively justified for both parties).

\footnotetext{
${ }^{12}$ Regarding political extremism, in addition to the well-documented polarization of politician actions and language, there has been an uptick in other forms of political behavior likely perceived as extreme such as government shut-downs, refusals to raise the federal debt ceiling, and blocked court appointments, including an extended delay for a Supreme Court Justice.
} 


\section{Data and Measurement}

The data set is the Caltech module of the 2011 CCES (1,000 respondents), again, first used by OS. This survey module includes questions on four general knowledge topics and on four economic topics, and corresponding questions on confidence in knowledge. OS use modules from the 2010 CCES as well; I use only the 2011 data for three reasons: 1) the 2011 data set includes general knowledge questions, while the 2010 modules include just economic questions (general knowledge questions are more standard in studies of overprecision); 2) the 2011 data set has questions on twice as many knowledge topics as the 2010 data set (eight versus four); 3) only the 2011 CCES includes party thermometer questions (questions on the favorability of each party, rated on a 0-100 scale; this is the standard variable used to study affective polarization). Table 1 presents the eight knowledge questions from the 2011 CCES, corresponding correct answers, and summary statistics for respondent answers. ${ }^{13}$

[Table 1]

Other papers on overconfidence typically measure this for individuals by comparing their actual accuracy of answers or coverage of confidence intervals to expected accuracy or coverage. OS discuss how overconfidence cannot be measured this way with the CCES data because it does not include a sufficient number of questions, as this would be infeasible for the survey, and because the CCES economic topic confidence questions are qualitative, which has the advantage of being more clearly understood by survey respondents than quantitative measures.

OS describe their method for measuring overprecision (which they refer to as overconfidence, but do note that the type of overconfidence that they study is oveprecision) as follows (p.511): "Confidence reflects both knowledge and overconfidence, so subtracting knowledge

\footnotetext{
${ }^{13}$ All general knowledge questions were followed by "Even if you are not sure, please give us your best guess." All economic questions were preceded by statements of the mean, high and low values of the variable since World War II. Both types of questions include qualitative measures of confidence, coded as categorical variables ranging from 1 to 6 , and the general knowledge questions also include quantitative measures of confidence ("what do you think is the percent chance that your best guess, entered above, is within - of the actual answer?", with the range referred to varying across the questions). For the general knowledge questions, to use all available confidence information, I use the average of the qualitative and percentage questions (each normalized to a scale of 0-1); results are similar when just the qualitative questions are used.
} 
from confidence leaves overconfidence. To subtract knowledge, we deduct points from a respondent's reported confidence based on his or her accuracy, and thus knowledge, on the corresponding factual question. This is implemented conservatively: we regress confidence on an arbitrary, fourth-order polynomial of accuracy, and use the residual as a measure of overconfidence." Overprecision is measured this way separately for each knowledge topic, for each respondent, and then an aggregate measure is constructed for each respondent as the first principal component of the topic-level measures. ${ }^{14}$

While this is a very reasonable procedure, it yields estimates of overprecision that are very highly correlated with pure confidence, so analysis using this measure could largely pick up pure confidence effects and not those of overconfidence. Their measure of overprecision has a 0.96 correlation with an analogous measure of confidence. OS note in their paper that all of their theoretical and empirical results hold when overconfidence is replaced with confidence, implying that separating confidence and overconfidence is not as crucial for their purposes as it is for mine in this paper.

I propose an alternative measure of overprecision that more directly accounts for the difference between confidence and knowledge (i.e., the difference between perceived and actual precision of beliefs). To do this, I first normalize confidence for respondent $i$ on topic $t$ to range from 0 to 1 , denoted by $C_{i t}$. This is equal to the fraction of possible confidence the respondent could have for the topic. For each topic, knowledge is bounded above (the correct answer) and bounded below (following OS, I top-code errors; more on this below). A natural definition of knowledge (for respondent $i$ on topic $t$ ) then with the same support and units as $C_{i t}$ is $K_{i t}=\frac{e_{t}^{*}-e_{i t}}{e_{t}^{*}}$, in which $e_{i t}$ denotes the absolute value of $i$ 's error for topic $t$, and $e_{t}^{*}$ denotes the maximum error for $t$.

Given that $K_{i t}$ and $C_{i t}$ have the same scale and (lack of) units, I can now apply OS's conceptual definition of overprecision directly. Letting $O P_{i t}$ denote overprecision for $i$ on

\footnotetext{
${ }^{14}$ Moore and Dev (2017) note that while it is intuitively and theoretically plausible that overconfidence would be a stable individual-level characteristic (as assumed by OS), prior literature has failed to support this idea. However, for overprecision in particular there is at least one study, Moore and Swift (2010), that "does seem to demonstrate more intra-individual consistency."
} 
topic $t$ :

$$
O P_{i t}=C_{i t}-K_{i t}
$$

This definition, while straightforward, makes a linearity assumption on the proper calibration of confidence: the marginal effects of (fractional) changes in both confidence (perceived "precision") and knowledge (actual "precision") are constant. ${ }^{15}$ Still, in addition to mapping directly to OS's conceptual definition of overconfidence, this definition of $O P$ has several attractive properties beyond OS's definition:

1. $O P$ is at its upper bound (for a given respondent-topic) when confidence is at its upper bound and knowledge at its lower bound (for that respondent-topic) (OP $P_{i t}=1$ if $K_{i t}=0$ and $\left.C_{i t}=1\right)$

2. $O P$ is at its lower bound when confidence is at its lower bound and knowledge at its upper bound $\left(O P_{i t}=-1\right.$ if $K_{i t}=1$ and $\left.C_{i t}=0\right)$.

3. $O P_{i t}=0$ when knowledge and confidence are "equal" $\left(K_{i t}=C_{i t}\right)$.

For this measure of $O P$, I follow OS in using the first principal component of the respondenttopic-level estimates of overconfidence to estimate respondent-level overconfidence (with all eight topics for most of the analysis). As mentioned above, OS top-code the absolute value of error for each question at the level approximately equal to the errors at the 5th and 95th percentiles for each question. The measure of $O P$ that I use in the paper uses the same topcoding as OS. ${ }^{16} \mathrm{OP}$ has a correlation of 0.62 with pure confidence, substantially lower than

\footnotetext{
${ }^{15}$ As OS discuss, this proper, or correct, calibration is unobservable with this data, and thus estimating overconfidence requires us to make some type of assumption.

${ }^{16}$ However, as Table 1 shows, the absolute values of errors for responses below and above the correct answer can vary substantially. The table also indicates that for some questions, the sign of the error is relevant to the interpretation. For example, when estimating the population of Spain, an answer of less than 5 million is closer to correct (44 million), in levels, than than an answer of 100 million, but the latter could be seen as more reasonable. To account for these issues, I construct an additional measure of $O P$ in which I use the actual (rounded) 5th and 95th percentiles for top-coding of errors, and use one value of $e^{*}$ for estimates greater than the true value ( $e$ at the 95th percentile answer) and one for estimates less than the true value ( $e$ at the 5 th percentile) for each topic ${ }^{17}$ and find that using this measure instead of the original one has very minor effects on all of the results.
} 
OS's correlation. In the appendix I discuss and present evidence of further validation of $O P$.

Figure 2 presents kernel densities of favorability ratings for each of the parties for respondents who are members of each party. The in-party and out-party ratings are similar across the two parties, but Democrats have a higher modal rating of the in-party. Figure 3 presents a smoothed plot of the relationship between $O P$ and the difference in party favorability ratings, $F_{D}$ (favorability difference), equal to $F_{O}-F_{I}\left(F_{0}, F_{I}=\right.$ out (in)-party favorability), providing a preview of the more detailed econometric results. Note that, to the extent that $O P$ is measured with error, this would attenuate results regarding its effects on the various outcome variables, strengthening the validity of such non-null results (and reducing the validity of null results).

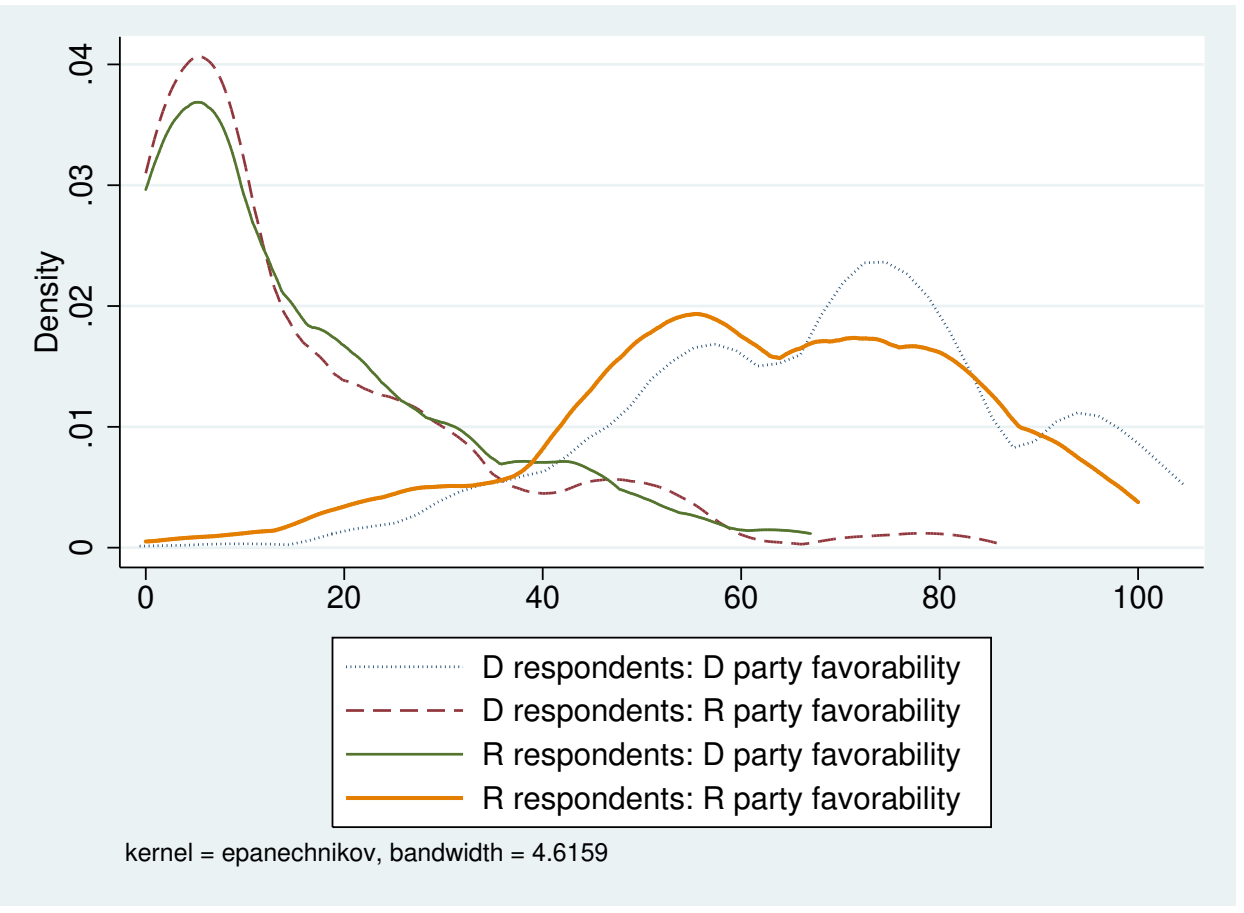

Figure 2: Kernel densities of party favorability ratings.

\section{Empirical Methods}

The methods that I use to estimate $O P$ effects are mostly straightforward: various dependent variables are regressed on $O P$, the set of economic and demographic control variables used by OS, and myriad alternative controls and interactions. The standard controls used in all of 


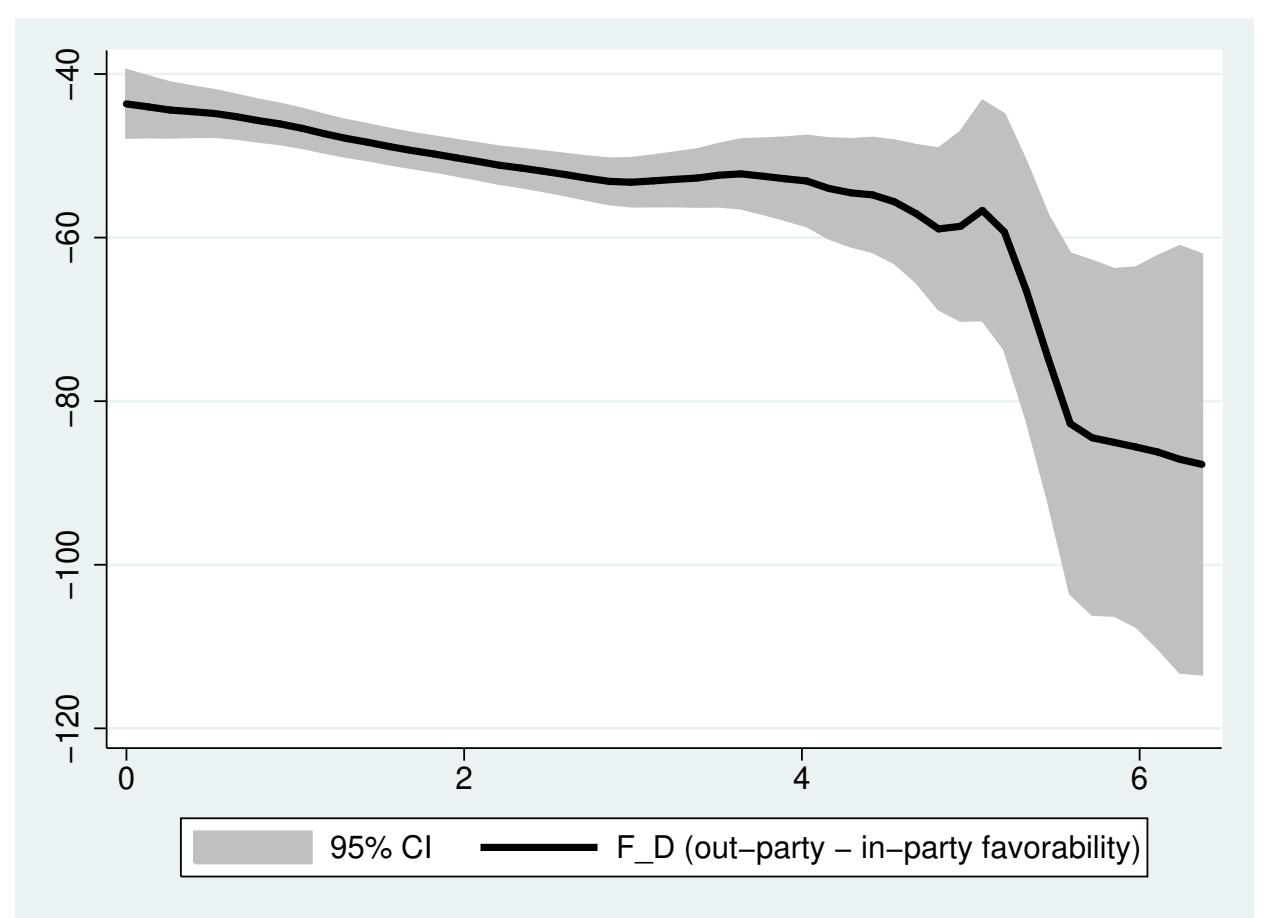

Figure 3: Smooth local polynomial plot of $O P$ (x-axis) vs $F_{D}$ (y-axis).

the analyses are fixed effects for income groups, education groups, union member (current or former), union household, home ownership, stock ownership, state, fourth order-polynomials in both age and a political knowledge/interest index. ${ }^{18}$ I also generally include as many ideology and partisanship control variables as possible to attempt to conservatively account for omitted factors that could bias $O P$ coefficients.

To test H1.A, I use "Distance" as the dependent variable, which is perceived ideological distance from the out-party relative to that of the in-party. ${ }^{19}$ For these analyses, I include as controls fixed effects for "Partisanship" (equal to 0,1 , or 2 for "lean" toward party but not

\footnotetext{
${ }^{18} \mathrm{My}$ sample size is smaller than OS's, so to preserve degrees of freedom I replace age fixed effects (which OS use in some of their analyses) with the (arbitrary) fourth order polynomial. The political knowledge/interest index (henceforth just political knowledge) is constructed as follows. The CCES includes eight questions on knowledge of current political representatives: the party of ["that has majority of seats of" in 2010 CCES]: 1) House; 2) Senate; 3) state Senate; 4) state House; 5) governor; 6) US Senator 1; 7) US Senator 2; 8) US House Representative. I create dummy variables for the answer "not sure" for each of these, and then use the first principal component of these eight dummies as the index.

${ }^{19}$ This is the absolute value of the difference between own ideology and perception of the outparty's ideology, minus the absolute value of this difference with respect to the in-party, with all ideologies measured on seven-point scales, and differences coded as zeroes for respondent's who answer "don't know" about the party's ideology.
} 
member, "not very strong" member, "strong" member, respectively), since partisan identity is not directly incorporated in the dependent variable.

To test H1.B and H1.C, I use self-reported ideological extremism ("Extremism," measured on a 0-1 scale) and Partisanship as dependent variables. ${ }^{20}$ For the former, I exclude ideology controls and Distance as it is a function of self-reported ideology, and include Partisanship fixed effects. For the latter, I exclude party strength on the right-hand-side (though do include a dummy for party, "Democrat"), but include Distance as a control variable, and ideology controls (non-linear functions of both self-reported ideology and issue-preference ideology estimated by Tausanovitch and Warshaw (2013)).

To test the H2's (and the latter parts of the H1's regarding effects on out-party dislike), I use the dependent variable of the difference in party favorabilities, $F_{D}$, as dislike is by nature comparative, and include Partisanship and Distance as regressors, and both types of ideology as additional controls. To test H2.B and H2.C, I interact $O P$ with measures of media consumption and education, as described further in the next section. To test H2.D, I use a dependent variable reflecting belief in the Obama "Birther" theory, described further in the next section.

I use Tobit models for the analysis of $F_{D}$ as the dependent variable because it is censored (from -100 to 0; I drop observations with $F_{D}>0$ as these likely reflect survey response errors) and OLS for all other models for computational simplicity and so estimated coefficients can be interpreted as average marginal effects. I use robust standard errors and use the survey weights whenever possible. ${ }^{21}$

For the analysis of each hypothesis, I examine pure confidence, $C$, as both a placebo independent variable (dropping $O P$ ), and as a control variable with $O P$ (results are similar when I replace $C$ with a measure of pure knowledge, and I cannot use both $C$ and knowledge

\footnotetext{
${ }^{20}$ Extremism is the average of the normalized deviation of the mid-point from self-reported ideology on 5- and 7-point scales.

${ }^{21}$ I do not cluster standard errors (OS clustered standard errors by age; for my analysis, this type of clustering yields smaller standard errors but is not clearly justified, so it is more conservative to use non-clustered robust standard errors). For some methods it is more convenient (or only possible) to treat the weights as analytic weights; for analysis in which both weight options are available, results are quite similar either way.
} 
as controls because of their collinearity with $O P$ ). For each hypothesis, I also examine three additional specifications. First, one that includes an interaction of $O P$ with Democrat. As mentioned in the Section 2, there may be asymmetries in behavior of the parties that justifies dislike. There may also be asymmetries in cognitive styles across members of the parties (see, e.g., Jost et al. (2003)).

Second, a specification that includes $M R$ as a control variable, which is an index of a respondent's propensity to engage in motivated reasoning/response. I construct $M R$ as follows. Previous literature shows that survey respondents answer questions about economic conditions more favorably when a co-partisan is in office as president and less favorably when the president is from the out-party (Bullock, 2009), and this is also the case for economic questions in the CCES data set. ${ }^{22}$ This phenomenon is relatively likely to be driven by motivated reasoning (respondents truly believe co-partisans perform relatively well because they are motivated to believe this) and/or because of expressive, or motivated, responding. Thus, respondent answers to these questions may reflect a general tendency toward motivated behavior, and so I construct a respondent-topic level measure of motivated reasoning/responding as:

$$
M R_{i t}=\left\{\begin{array}{l}
\left(\frac{e_{i t}}{e_{t}^{*}}\right) \times C_{i t} \text { if } e_{i t} \text { is "motivated"; } \\
0 \text { otherwise. }
\end{array}\right.
$$

$e_{i t}$ is defined as "motivated" if it is in the direction favorable politically to the respondent, given her party (good economic conditions for Democrats, bad conditions for Republicans). This variable is thus increasing in both the favorability of the stated answer (difference between that answer and truth) and respondent's confidence in the answer, with a positive interaction. It is fairly clear that motivated reasoning would cause Republicans to state lower job growth

\footnotetext{
${ }^{22}$ Democrat respondents consistently described and predicted more favorable economic conditions than Republicans; the mean (without top-coding) responses to the question on job changes in the last year were -4.2 (million) for Democrats and -6.1 for Republicans; on predicted job changes, 0.89 and -2.44, respectively; on inflation last year, $8.31 \%$ and $10.19 \%$ (resp.) and on predicted inflation, $5.34 \%$ and $8.05 \%$. The signs of each of the differences are the same (though magnitudes smaller) when restricting the sample to the most highly educated group.
} 
numbers and higher inflation, and cause Democrats to state larger job growth numbers. It is less clear what ideal inflation would be for Democrats, and thus to be conservative I use only the two job questions for $M R_{i t}$. There are two other survey questions that are useful for this purpose, on the respondent's perception of recent performance of the national economy (1-5 scale) and the unemployment rate, which I adjust based on the respondent's party so that a higher number represents a more "motivated" answer (and arbitrarily top-code unemployment at 20\%). I use the first principal component across these four measures per respondent to estimate a respondent-level measure, $M R_{i}$; for the analysis that includes $M R$ I use a version of $O P$ based only on general knowledge questions, since $M R$ incorporates the economic questions. In the appendix, I provide evidence of validity of $M R$, and the distinction between $O P$ and $M R$ is demonstrated further in the birther theory analysis. ${ }^{23} M R$ is certainly not a perfect measure of motivated reasoning, but it is still useful to examine if $O P$ estimates are robust to its inclusion.

The third alternative specification is one in which I account for measurement error in $O P$ using instrumental variable (IV) estimation. Ortoleva and Snowberg (2015a) construct two measures of $O P$, one using just the general knowledge questions and one using just economic questions, and account for measurement error by instrumenting for each measure using the other (estimating two separate IV models). Given this set-up (two noisy measures of a variable, with neither being a priori superior to the other), Gillen et al. (forthcoming) suggest that an alternative procedure is more efficient, which I follow. ${ }^{24}$

${ }^{23}$ I (arbitrarily) top-code unemployment guesses at 20\%. I examined several variants on this definition of $M R$, including using all four economic questions, using negative values for responses unfavorable to the co-party, using just the economic knowledge questions, and using just the survey questions on economic performance without confidence measures, and different types of top-coding, and obtained generally similar results, though validation results are much weaker without the economic knowledge questions.

${ }^{24}$ This procedure is to combine the measures by duplicating and stacking the data set, and creating two variables, one equal to the first measure for the first half of observations and the second measure for the second half, and the second variable the reverse (second measure for first half, first measure for second), and then using one as IV for the other (and clustering standard errors by the initial observation identifier). 


\section{Results}

I standardize variables whose scales are difficult to interpret, $O P$ (overprecision), $M R$ (motivated reasoning), $C$ (confidence); each unit of these variables now equals one standard deviation of the original variable. Table 2 presents results for the analysis of the H1's. Panel A presents analysis of H1.A. Three of the five $O P$ estimates are insignificant; the $O P$ coefficient is significant at $10 \%$ in the baseline model and at $5 \%$ when $C$ is included, and negative in both cases, which is inconsistent withh H1. These results provide some evidence that, conditional on this large set of controls, extremism declines as $O P$ increases, i.e., that being more extreme is "more rational" (having more accurately calibrated confidence in one's knowledge). An explanation for this phenomenon could be that extremism entails private, social identity-related benefits, consistent with claims discussed by (Kahan et al., 2012, 2013). However, these results are non-robust and far from conclusive; none of the estimates are significant at $1 \%$ and in three of the five specifications the estimates are not even significant at $10 \%$.

The results for H1.B are quite similar to those for H1.A, which is not surprising given that both dependent variables (Extremism and Distance) are direct functions of the respondent's self-reported ideology. Estimated $O P$ effects are substantially stronger and more significant for H1.C, regarding the Partisanship dependent variable. The results support the hypothesis: that $O P$ increases strength of partisanship. The baseline model indicates that a one standard deviation increase in $O P$ predicts an increase in expected level of party strength of 0.14 ; the IV estimate is 0.438 . The estimate for the placebo variable, $C$, is near zero and insignificant. Including $M R$ reduces the $O P$ effect to 0.095 , but it remains significant at $5 \%$. The interaction coefficient is insignificant, failing to support effects varying by party. ${ }^{25}$

[Table 2]

Table 3 presents results for analysis of H2.A. Results for $O P$ are all significant at $5 \%$ or $1 \%$ and supportive of H2.A. The baseline model implies a one standard deviation increase in $O P$

\footnotetext{
${ }^{25}$ The simplest way to reconcile the conflicting results here - the results supporting the opposite of H1.A and H1.B, and results supporting H1.C - is to simply discount the former, since they are less robust. However, the two types of results could both be valid, since the dependent variables are distinct, but I refrain from further speculation here.
} 
predicts about a five point decline in relative out-party favorability, and a 16 point decline for the IV model. The placebo effect $(C)$ is much smaller, and disappears when included with $O P$. The results also indicate that a one unit increase in Partisanship predicts an approximately 7.5 point decrease in out-party dislike ( 5 points in IV model). Taking the products of these estimates with the baseline and IV OP coefficients from Panel $\mathrm{C}$ of Table 2 , the indirect effects of a standard deviation increase in $O P$ on dislike range from 1.05 to 2.2 points. The combined (direct plus indirect) IV effect of 18.2 favorability points (per $O P$ standard deviation) is $71 \%$ of one standard deviation in $F_{D}$. Again, there is no significant variation in effects across parties.

[Table 3]

In Table 4, I report results for interactions of four dummy variables with $O P$ to examine heterogeneity in $O P$ 's direct effects on $F_{D}$, and to address H2.B and H2.C. The dummies are indicators for being above the median in age, education, income, and media exposure. ${ }^{26}$ Only the age interaction term is significant; it is positive and about the same magnitude as the $O P$ coefficient, indicating that $O P$ has a near-zero overall effect for respondents whose age is above the median. The (unreported) non-interacted high age dummy coefficient is approximately -15 (over twice the $O P$ coefficient, and just over the IV $O P$ coefficient from Table 4). These results together imply that overprecision drives dislike for younger people only, and that transitioning to the older age group has the same effect on dislike as moving about half-way up the $O P$ distribution. This age effect is consistent with Boxell et al. (2017). The other interactions, which more directly address the hypotheses, are insignificant.

These results provide fairly strong support for H2.C (that overprecision effects do not increase with cognitive ability, proxied crudely by education), but fail to support H2.B (that overprecision effects increase with media exposure). The media interaction may be attenuated due to counter-acting effects (e.g., media exposure could be positively correlated with an aspect of cognition that reduces $F_{D}$, nullifying the positive effect from exposure to more out-party

\footnotetext{
${ }^{26} \mathrm{I}$ use OS's measure of media exposure, which is the first principal component of four variables, each assessing use of a different type of media in the past 24 hours (blog, TV, radio, newspaper). The sample is smaller for the model with the income interaction because I drop respondents who answered "prefer not to say" (which was not an option for other questions).
} 
information). Moreover, the media variable is admittedly a quite noisy measure of media exposure. It is also possible that quantity of media exposure does not matter as much as type of media exposure (which I do not have data on) — or even that overprecision direct effects occur mainly through mechanisms other than media.

[Table 4]

Table 3 suggests that $O P$ directly causes dislike, but does not show specifically how $O P$ does this, i.e., which beliefs, if any, that $O P$ might affect that in turn drive dislike. To address this issue (H2.D), I conduct an auxiliary analysis in which I examine $O P$ effects on a variable capturing belief in the Obama "birther" theory (the theory that he was not born in the US, Birther, equal to $1,2, \ldots, 5$ (strongest belief in the theory)). This variable measures beliefs on a factual, though perhaps ambiguous, issue. The Caltech module includes questions on several other factual issues but I restrict attention to the birther question because responses vary by party most substantially (by a wide margin), suggesting its importance for partisan affect. I conduct this analysis separately for Republicans and Democrats as multiple coefficients are expected to vary by party. I examine the effects of $O P$ and $M R$ on Birther, and also the effects of Birther on $F_{D}$.

Table 5 presents these results. They imply that higher $O P$ predicts belief in the birther theory for Republicans, and this effect is robust to including the $M R$ control. The results also imply that birther belief contributes to hostility, as Birther predicts lower $F_{D}$ for Republicans. Results also show that $M R$ drives disbelief in the birther theory for Democrats; the sign of the $M R$ effect for Republicans is as expected but it is not quite significant. $O P$ has a marginally significant positive effect on Birther for Democrats; this might seem surprising, but is reasonable given the prevalence of the theory, and also supports the difference between measured unmotivated and motivated bias. Democrats who were simply more prone to believe what they hear might have been more likely to believe the theory. These results support $O P$ having effects on factual issues that could affect partisan feelings, and support $O P$ effects being distinct from $M R$ effects. The results also hint at differences in various effects across the parties, which would require a larger sample to carefully explore. 
[Table 5]

\section{Concluding Remarks}

Dislike causes bias: people tend to be biased against things they dislike because they dislike them, political parties included. This paper examines and provides evidence in support of causality in the other direction: bias being the source of dislike. I find that the bias of overprecision does not predict ideological extremism or a measure of partisan social distance, but that this bias does predict: 1) stronger partisan identity (which in turn predicts out-party dislike), 2) a direct increase in out-party dislike, holding fixed ideology and partisanship, and 3) beliefs about a factual issue, which in turn predict dislike. The results augment the better established literature arguing that dislike is caused in part by beliefs that may be biased by motivated forces. Dislike is likely also caused by beliefs that are biased more incidentally.

Again, these results do not at all rule out other explanations for partyism, which almost surely has many causes. Moreover, even if one questions the distinction that I draw between motivated and unmotivated bias (in general, or regarding the interpretation of the particular estimates reported in this paper), and prefers to interpret this paper's results as reflecting general cognitive bias effects, these results are, I would argue, still an important contribution to the literature on this phenomenon. The empirical relationship established between bias and partisan hostility clarifies the notion that competing partisans normatively should not dislike each other as much as they do - that the dislike is driven in part by perceptions that are objectively false, and dislike could be abated if each side could understand the other (and itself) better. Public awareness of partyism being caused by cognitive errors could even help mitigate partyism, by increasing both intrinsic and social incentives to do so.

There are several aspects of this paper that could be improved in future work. First, there is the lack of experimental variation. One way to make progress in this regard would be to measure respondent-level overprecision, then present respondents with suggestive but noisy information indicating the out-party (in-party) is a bad (good) actor, and measure effects of this information on affect. If respondents who are generally more overconfident in beliefs 
demonstrate stronger reactions to the noisy information, this would support H2.A. Another possibility would be to present respondents with information on their own overprecision and see if this moderates overprecision and consequently partisan affect outcomes. The second issue that could be improved upon is the measure of overprecision - although it is based on questions standard in this literature, these questions are not tailored to the context of politics or inter-personal beliefs. It is possible that modifying these questions could improve the overprecision measure for this context. Perhaps some people are particularly overconfident in their judgments of other people, rather than knowledge in general, and if so, we would expect this interpersonal overconfidence to be most relevant to partyism. Similarly, it may be possible to obtain a better measure of motivated reasoning as a distinct factor. Third, the analysis of heterogeneity, by party and other factors, was limited, mainly due to sample size; increasing this is of course costly, but feasible and potentially worthwhile.

\section{References}

A. Abramowitz and S. Webster. All politics is national: The rise of negative partisanship and the nationalization of us house and senate elections in the 21st century. In Annual Meeting of the Midwest Political Science Association Conference, pages 16-19, 2015.

D. J. Ahler. Self-fulfilling misperceptions of public polarization. The Journal of Politics, 76 (03):607-620, 2014.

J. Andreoni and T. Mylovanov. Diverging opinions. American Economic Journal: Microeconomics, 4(1):209-232, 2012.

C. Andris, D. Lee, M. J. Hamilton, M. Martino, C. E. Gunning, and J. A. Selden. The rise of partisanship and super-cooperators in the us house of representatives. PloS one, 10(4): e0123507, 2015.

M. J. Barber and N. McCarty. Causes and consequences of polarization. Solutions to Political Polarization in America, page 15, 2015. 
R. Bénabou and J. Tirole. Mindful economics: The production, consumption, and value of beliefs. The Journal of Economic Perspectives, 30(3):141-164, 2016.

L. Boxell, M. Gentzkow, and J. M. Shapiro. Greater internet use is not associated with faster growth in political polarization among us demographic groups. Proceedings of the National Academy of Sciences, page 201706588, 2017.

J. G. Bullock. Partisan bias and the bayesian ideal in the study of public opinion. The Journal of Politics, 71(03):1109-1124, 2009.

B. Caplan. Rational irrationality and the microfoundations of political failure. Public Choice, 107(3-4):311-331, 2001.

B. Caplan. Systematically biased beliefs about economics: robust evidence of judgemental anomalies from the survey of americans and economists on the economy. The Economic Journal, 112(479):433-458, 2002.

J. R. Chambers and D. Melnyk. Why do i hate thee? conflict misperceptions and intergroup mistrust. Personality and Social Psychology Bulletin, 32(10):1295-1311, 2006.

J. R. Chambers, B. R. Schlenker, and B. Collisson. Ideology and prejudice the role of value conflicts. Psychological science, page 0956797612447820, 2013.

I.-H. Cheng and A. Hsiaw. Distrust in experts and the origins of disagreement. 2017.

R. D. Congleton. Rational ignorance, rational voter expectations, and public policy: A discrete informational foundation for fiscal illusion. Public Choice, 107(1-2):35-64, 2001.

F. L. L. de Leon and R. Rizzi. Does forced voting result in political polarization? Public Choice, 166(1-2):143-160, 2016.

J. M. DeVault. Political polarization, congressional redistricting, and trade liberalization. Public Choice, 157(1-2):207-221, 2013.

I. Esponda and D. Pouzo. Retrospective voting and party polarization. Technical report, Working Paper, UC Berkeley, 2016. 
P. M. Fernbach, T. Rogers, C. R. Fox, and S. A. Sloman. Political extremism is supported by an illusion of understanding. Psychological science, page 0956797612464058, 2013.

R. G. Fryer Jr, P. Harms, and M. O. Jackson. Updating beliefs with ambiguous evidence: Implications for polarization. Technical report, National Bureau of Economic Research, 2013.

M. Gentzkow, J. M. Shapiro, and M. Taddy. Measuring polarization in high-dimensional data: Method and application to congressional speech. 2015.

B. Gillen, E. Snowberg, and L. Yariv. Experimenting with measurement error: Techniques with applications to the caltech cohort study. Technical report, Journal of Political Economy, forthcoming.

J. Graham, J. Haidt, and B. A. Nosek. Liberals and conservatives rely on different sets of moral foundations. Journal of personality and social psychology, 96(5):1029, 2009.

J. D. Greene. Moral tribes: Emotion, reason, and the gap between us and them. Penguin, 2014.

M. D. Grubb. Overconfident consumers in the marketplace. The Journal of Economic Perspectives, 29(4):9-35, 2015.

J. Haidt. The righteous mind: Why good people are divided by politics and religion. Vintage, 2012.

M. J. Hetherington and T. J. Rudolph. Why Washington Won't Work: Polarization, Political Trust, and the Governing Crisis, volume 104. University of Chicago Press, 2015.

S. J. Hill and C. Tausanovitch. A disconnect in representation? comparison of trends in congressional and public polarization. The Journal of Politics, 77(04):10581075, 2015.

E. I. Hoppe and D. J. Kusterer. Behavioral biases and cognitive reflection. Economics Letters, 110(2):97-100, 2011. 
G. A. Huber and N. Malhotra. Political homophily in social relationships: Evidence from online dating behavior. The Journal of Politics, 79(1):269-283, 2017.

S. Iyengar and S. J. Westwood. Fear and loathing across party lines: New evidence on group polarization. American Journal of Political Science, 59(3):690-707, 2015.

S. Iyengar, G. Sood, and Y. Lelkes. Affect, not ideology a social identity perspective on polarization. Public Opinion Quarterly, 76(3):405-431, 2012.

A. Jha, C. J. Boudreaux, and V. Banerjee. Political leanings and social capital. Journal of Behavioral and Experimental Economics, 72:95-105, 2018.

J. T. Jost, J. Glaser, A. W. Kruglanski, and F. J. Sulloway. Political conservatism as motivated social cognition. Psychological bulletin, 129(3):339, 2003.

D. Kahan et al. Why we are poles apart on climate change. Nature, 488(7411):255-255, 2012.

D. M. Kahan. The politically motivated reasoning paradigm, part 1: What politically motivated reasoning is and how to measure it. Emerging Trends in the Social and Behavioral Sciences: An Interdisciplinary, Searchable, and Linkable Resource, 2016.

D. M. Kahan, E. Peters, E. C. Dawson, and P. Slovic. Motivated numeracy and enlightened self-government. Yale Law School, Public Law Working Paper, (307), 2013.

D. Laibson and R. Zeckhauser. Amos tversky and the ascent of behavioral economics. Journal of Risk and Uncertainty, 16(1):7-47, 1998.

Y. Lelkes. Mass polarization: Manifestations and measurements. Public Opinion Quarterly, page nfw005, 2016.

Y. Lelkes, G. Sood, and S. Iyengar. The hostile audience: The effect of access to broadband internet on partisan affect. American Journal of Political Science, 2015.

M. Levendusky and N. Malhotra. Does media coverage of partisan polarization affect political attitudes? Political Communication, pages 1-19, 2015. 
R. Levy. Soothing politics. Journal of Public Economics, 120:126-133, 2014.

G. J. Martin and A. Yurukoglu. Bias in cable news: Persuasion and polarization. American Economic Review, 107(9):2565-99, 2017.

L. Mason. "i disrespectfully agree": The differential effects of partisan sorting on social and issue polarization. American Journal of Political Science, 59(1):128-145, 2015.

L. Mason. Uncivil agreement: How politics became our identity. University of Chicago Press, 2018.

D. A. Moore and A. S. Dev. Inidividual differences in overconfidence. In Encyclopedia of Personality and Individual Differences. Springer, 2017.

D. A. Moore and P. J. Healy. The trouble with overconfidence. Psychological review, 115(2): $502,2008$.

D. A. Moore and S. A. Swift. The three faces of overconfidence in organizations. Social psychology of organizations, pages 147-184, 2010.

D. A. Moore, E. R. Tenney, and U. Haran. Overprecision in judgment. The Wiley Blackwell handbook of judgment and decision making, pages 182-209, 2015.

D. A. Moore, E. R. Tenney, and U. Haran. Overprecision in judgment. Handbook of judgment and decision making. New York: Wiley, pages 182-212, 2016.

U. Neisser. Cognitive psychology, new york: Appleton-century-crofts, 1967. NeisserCognitive Psychology1967, 1971.

M. Noori. Cognitive reflection as a predictor of susceptibility to behavioral anomalies. Judgment and Decision Making, 11(1):114, 2016.

P. Ortoleva and E. Snowberg. Are conservatives overconfident? European Journal of Political Economy, 40:333-344, 2015a. 
P. Ortoleva and E. Snowberg. Overconfidence in political behavior. American Economic Review, 105(2):504-535, 2015b.

L. Pessoa. On the relationship between emotion and cognition. Nature reviews neuroscience, $9(2): 148-158,2008$.

J. K. Rempel and S. Sutherland. Hate: Theory and implications for intimate relationships. In The Psychology of Love and Hate in Intimate Relationships, pages 105-129. Springer, 2016.

R. J. Robinson, D. Keltner, A. Ward, and L. Ross. Actual versus assumed differences in construal: "naive realism" in intergroup perception and conflict. Journal of Personality and Social Psychology, 68(3):404, 1995.

J. C. Rogowski and J. L. Sutherland. How ideology fuels affective polarization. Political Behavior, pages 1-24, 2015.

J. Schnellenbach and C. Schubert. Behavioral political economy: A survey. European Journal of Political Economy, 40:395-417, 2015.

J. S. Selinger. Embracing Dissent: Political Violence and Party Development in the United States. University of Pennsylvania Press, 2016.

D. F. Stone. Just a big misunderstanding? Bias and Bayesian affective polarization. SSRN Working Paper, 2016.

C. R. Sunstein. Partyism. U. Chi. Legal F., page 1, 2015.

H. E. Tajfel. Differentiation between social groups: Studies in the social psychology of intergroup relations. Academic Press, 1978.

C. Tausanovitch and C. Warshaw. Measuring constituent policy preferences in congress, state legislatures, and cities. The Journal of Politics, 75(02):330-342, 2013.

P. Tetlock and D. Gardner. Superforecasting: The art and science of prediction. Random House, 2015. 
J. Westfall, L. Van Boven, J. R. Chambers, and C. M. Judd. Perceiving political polarization in the united states party identity strength and attitude extremity exacerbate the perceived partisan divide. Perspectives on Psychological Science, 10(2):145-158, 2015.

S. J. Westwood, S. Iyengar, S. Walgrave, R. Leonisio, L. Miller, and O. Strijbis. The tie that divides: Cross-national evidence of the primacy of partyism. European Journal of Political Research, 2015. 


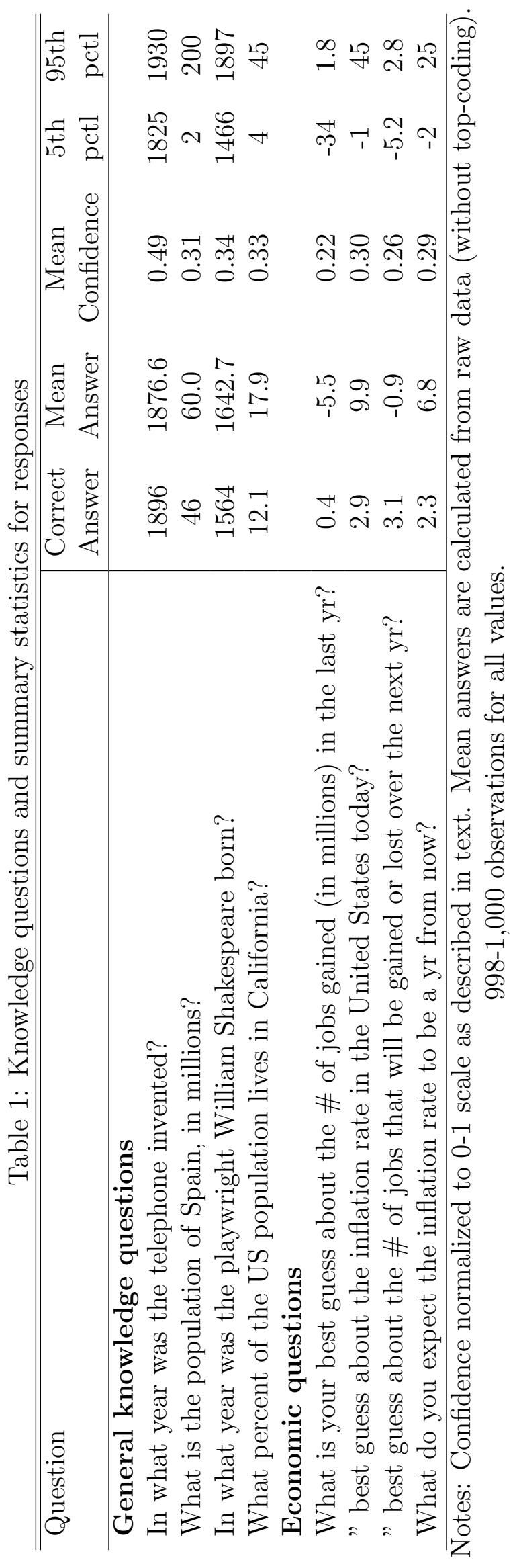


Table 2: Analysis of H1.A, H1.B, and H1.C

\begin{tabular}{|c|c|c|c|c|c|c|}
\hline \multicolumn{7}{|c|}{ Panel A: H1.A (Dependent variable = Distance) } \\
\hline$O P$ & $\begin{array}{c}-0.068^{*} \\
(0.039)\end{array}$ & & $\begin{array}{c}-0.122^{* *} \\
(0.054)\end{array}$ & $\begin{array}{l}-0.100 \\
(0.061)\end{array}$ & $\begin{array}{c}-0.053 \\
(0.036)\end{array}$ & $\begin{array}{c}-0.239 \\
(0.146)\end{array}$ \\
\hline$C$ & & $\begin{array}{l}-0.003 \\
(0.018)\end{array}$ & $\begin{array}{c}0.036 \\
(0.025)\end{array}$ & & & \\
\hline$O P \times$ Dem & & & & $\begin{array}{c}0.052 \\
(0.078)\end{array}$ & & \\
\hline$M R$ & & & & & $\begin{array}{l}-0.030 \\
(0.045)\end{array}$ & \\
\hline \multicolumn{7}{|c|}{ Panel B: H1.B (Dependent variable = Extremism) } \\
\hline$O P$ & $\begin{array}{c}-0.025^{*} \\
(0.015)\end{array}$ & & $\begin{array}{c}-0.046^{* *} \\
(0.020)\end{array}$ & $\begin{array}{c}-0.016 \\
(0.023)\end{array}$ & $\begin{array}{c}0.001 \\
(0.014)\end{array}$ & $\begin{array}{l}-0.069 \\
(0.051)\end{array}$ \\
\hline$C$ & & $\begin{array}{l}-0.000 \\
(0.007)\end{array}$ & $\begin{array}{l}0.015^{*} \\
(0.009)\end{array}$ & & & \\
\hline$O P \times$ Dem & & & & $\begin{array}{c}-0.014 \\
(0.028)\end{array}$ & & \\
\hline$M R$ & & & & & $\begin{array}{c}0.012 \\
(0.014)\end{array}$ & \\
\hline \multicolumn{7}{|c|}{ Panel C: H1.C (Dependent variable = Partisanship) } \\
\hline$O P$ & $\begin{array}{c}0.140^{* * *} \\
(0.040)\end{array}$ & & $\begin{array}{c}0.178^{* * *} \\
(0.053)\end{array}$ & $\begin{array}{c}0.069 \\
(0.062)\end{array}$ & $\begin{array}{c}0.095^{* *} \\
(0.037)\end{array}$ & $\begin{array}{c}0.438^{* * *} \\
(0.168)\end{array}$ \\
\hline Distance & $\begin{array}{c}0.104^{* *} \\
(0.051)\end{array}$ & $\begin{array}{c}0.093^{*} \\
(0.052)\end{array}$ & $\begin{array}{c}0.107^{* *} \\
(0.051)\end{array}$ & $\begin{array}{c}0.102^{* *} \\
(0.051)\end{array}$ & $\begin{array}{c}0.112^{* *} \\
(0.052)\end{array}$ & $\begin{array}{c}0.134^{* *} \\
(0.053)\end{array}$ \\
\hline$C$ & & $\begin{array}{c}0.032 \\
(0.020)\end{array}$ & $\begin{array}{l}-0.026 \\
(0.026)\end{array}$ & & & \\
\hline$O P \times$ Dem & & & & $\begin{array}{c}0.115 \\
(0.082)\end{array}$ & & \\
\hline$M R$ & & & & & $\begin{array}{c}0.022 \\
(0.043)\end{array}$ & \\
\hline Model & OLS & OLS & OLS & OLS & OLS & IV \\
\hline $\mathrm{N}$ & 739 & 739 & 739 & 739 & 736 & 1478 \\
\hline
\end{tabular}

Notes: All models estimated using survey weights, with economic, demographic, and political knowledge controls, and robust standard errors (clustered by respondent for IV model, which uses duplicated data set). Panels A and B models include Partisanship fixed effects, and Panels $\mathrm{A}$ and $\mathrm{C}$ models include self-reported ideology and issue-based ideology controls. All control variables described in text. $*, * *, * * *$ denote $10 \%, 5 \%, 1 \%$ significance. 
Table 3: Analysis of H2.A (Dependent Variable $=F_{D}$ )

\begin{tabular}{|c|c|c|c|c|c|c|}
\hline & OLS & OLS & OLS & OLS & OLS & IV \\
\hline$O P$ & $\begin{array}{c}-5.037^{* * * *} \\
(1.241)\end{array}$ & & $\begin{array}{c}-4.879^{* * *} \\
(1.724)\end{array}$ & $\begin{array}{c}-4.073^{* *} \\
(1.700)\end{array}$ & $\begin{array}{c}-2.919^{* *} \\
(1.140)\end{array}$ & $\begin{array}{c}-16.035^{* *} \\
(6.923)\end{array}$ \\
\hline Partisanship & $\begin{array}{c}-7.524^{* * *} \\
(1.394)\end{array}$ & $\begin{array}{c}-8.118^{* * *} \\
(1.412)\end{array}$ & $\begin{array}{c}-7.533^{* * *} \\
(1.395)\end{array}$ & $\begin{array}{c}-7.468 * * * \\
(1.387)\end{array}$ & $\begin{array}{c}-7.788^{* * *} \\
(1.400)\end{array}$ & $\begin{array}{c}-5.058^{* *} \\
(2.025)\end{array}$ \\
\hline Distance & $\begin{array}{c}-9.612^{* * * *} \\
(1.648)\end{array}$ & $\begin{array}{c}-9.157^{* * *} \\
(1.677)\end{array}$ & $\begin{array}{c}-9.598^{* * *} \\
(1.656)\end{array}$ & $\begin{array}{c}-9.597^{* * *} \\
(1.652)\end{array}$ & $\begin{array}{c}-9.550^{* * *} \\
(1.660)\end{array}$ & $\begin{array}{c}-10.380^{* * * *} \\
(1.814)\end{array}$ \\
\hline C & & $\begin{array}{c}-1.667^{* * *} \\
(0.589)\end{array}$ & $\begin{array}{l}-0.106 \\
(0.801)\end{array}$ & & & \\
\hline$O P \times$ Dem & & & & $\begin{array}{l}-1.581 \\
(2.469)\end{array}$ & & \\
\hline$M R$ & & & & & $\begin{array}{c}0.348 \\
(1.205)\end{array}$ & \\
\hline $\mathrm{N}$ & 739 & 739 & 739 & 739 & 736 & 1478 \\
\hline
\end{tabular}

Notes: All models estimated using survey weights, with economic, demographic, political knowledge, self-reported ideology, issue-based ideology controls, and robust standard errors (clustered by respondent for IV model, which uses duplicated data set). *, **, *** denote $10 \%, 5 \%, 1 \%$ significance.

Table 4: Analysis of H2.B and H2.C (Dependent Variable $=F_{D}$ )

\begin{tabular}{lcccc}
\hline \hline & $(1)$ & $(2)$ & $(3)$ & $(4)$ \\
\hline$O P$ & $-6.835^{* * *}$ & $-5.274^{* * *}$ & $-4.478^{* *}$ & $-4.697^{* *}$ \\
& $(1.532)$ & $(1.505)$ & $(1.750)$ & $(2.092)$ \\
& $6.006^{* * *}$ & & & \\
$O P \times I(>$ age median $)$ & $(2.034)$ & & & \\
& & 2.268 & & \\
$O P \times I(>$ income median $)$ & & $(2.294)$ & & \\
& & & -0.825 & \\
$O P \times I(>$ media median $)$ & & & & 0.192 \\
$\mathrm{~N}$ & 739 & 739 & 651 & 739 \\
\hline
\end{tabular}

Notes: All models estimated using survey weights, with non-interacted respective indicator variable, Partisanship, economic, demographic, political knowledge, self-reported ideology, issue-based ideology controls, and robust standard errors . *, **, *** denote $10 \%, 5 \%, 1 \%$ significance. 
Table 5: Analysis of H2.D

\begin{tabular}{lcccc|cccc}
\hline \hline & \multicolumn{4}{c}{ Republicans } & \multicolumn{5}{c}{ Democrats } \\
& Dep var: Birther & \multicolumn{2}{c}{ Dep var: $F_{D}$} & Dep var: Birther & Dep var: $F_{D}$ \\
\hline$O P$ & $0.381^{* * *}$ & $0.252^{* *}$ & $-4.014^{* *}$ & $-2.852^{*}$ & 0.080 & $0.119^{*}$ & $-3.482^{*}$ & $-3.665^{* *}$ \\
& $(0.098)$ & $(0.100)$ & $(1.673)$ & $(1.703)$ & $(0.077)$ & $(0.068)$ & $(1.773)$ & $(1.763)$ \\
Party St. & 0.156 & 0.195 & $-5.899^{* * *}$ & $-5.424^{* *}$ & $0.137^{*}$ & $0.147^{*}$ & $-8.974^{* * *}$ & $-9.289^{* * *}$ \\
& $(0.118)$ & $(0.119)$ & $(2.133)$ & $(2.140)$ & $(0.080)$ & $(0.078)$ & $(1.908)$ & $(1.883)$ \\
Distance & -0.122 & -0.186 & $-13.567^{* * *}$ & $-13.938^{* * *}$ & $-0.281^{* * *}$ & $-0.280^{* * *}$ & $-9.809^{* * *}$ & $-9.165^{* * *}$ \\
& $(0.130)$ & $(0.143)$ & $(2.690)$ & $(2.557)$ & $(0.091)$ & $(0.085)$ & $(2.237)$ & $(2.260)$ \\
$M R$ & & 0.133 & & & & $-0.302^{* * *}$ & & \\
& & $(0.087)$ & & & & $(0.098)$ & & 2.295 \\
Birther & & & & $-3.048^{* *}$ & & & & $(1.977)$ \\
\hline N & 338 & 337 & 338 & 338 & 401 & 399 & 401 & 401
\end{tabular}

Notes: All models estimated using OLS with survey weights and economic, demographic, political knowledge, self-reported ideology, issue-based ideology, party and party strength controls (described in text), and robust standard errors. *, **, *** denote $10 \%, 5 \%, 1 \%$ significance. 